\title{
Accounting Problems and Countermeasures in SME
}

\author{
Xiumei Li \\ Weifang University of Science and Technology, Shouguang, Weifang,Shandong, 262700 China
}

\begin{abstract}
SMEs in the national economy is an important part of maintaining market stability, and it has a very important role for the operation to ensure a rational pricing mechanism and to ensure full employment and promote sustained and healthy develop, and it ensures social stability. However, the presence of SMEs in the financial control is weak; problems of accounting information distortion and other issues limit itself to develop, and we do some research on the current problems and countermeasures of SME financial management.
\end{abstract}

Keywords-SMEs; accounting management; countermeasure.

\section{ANALYSIS OF CURRENT SITUATION OF SMES ACCOUNTING WORK}

In recent years, the rapid development of China's SMEs plays an important role to stimulate private investment, ease employment pressure and maintain social stability, but at the same time, in the development of SMEs also exposed more and more problems, in which Accounting work is a more prominent issue, and accounting work is an important part of enterprise management, and it is related to the survival and development of enterprises, SMEs achieve sustainable development, we must pay attention to the management of the accounting work. In a market economy, enterprises continue to affect the competitive environment in the SME managers, and many small and medium enterprises in their efforts are to overcome their own weaknesses, and it constantly improves accounting management to create conditions for the enterprises themselves and their competitiveness. Therefore to increase the SME management accounting change, update accounting management, better promote the healthy development of SMEs, SME accounting work for the development of enterprises plays an important role, but at this stage it still has some problems, some quite serious problems. Finally, to establish strict financial control system is in order to make a more detailed accounting of the work carried out, on the one hand we establish the scope of the control system of authorization and approval, authorization is expressly approved SME accounting work, authority, procedures, etc. it will be the specific scope of concrete. On the other hand the establishment of separate post system strengthens the management duties. SMEs accountants post more than one person, unknown circumstances are required to implement these appropriate countermeasures in order to balance the powers and responsibilities, mutual cooperation,

Common mode of action is to achieve accounting work to strengthen the science and accounting purposes to improve the degree of specialization.

\section{ACCOUNTING PROBLEMS}

\section{A. Accounting staff quality is not high}

Particularity of accounting work for accounting professionals put forward higher requirements in ethics and the ability. Accounting work is closely with digital money, which requires accounting staff has a sense of integrity and a strong sense of responsibility, but at this stage, many employees face the temptation of money to the money under the abyss, which leads to the phenomenon of some digital distortion, affecting the healthy development of enterprises. Then, in the SME and corporate accountants in the presence of representatives of nepotism, they lack training and learning track, often appear accounting principle error, technical error, resulting in accounting allowed, operating results response distortion. In the era of transformation, they lack the new system of learning new regulations, lack finance for emerging computer learning and application, resulting in confusion accounting, which leads to highly irregular result of the lack of a new era and accounting personnel, ultimately it is not conducive to SME development.

\section{B. Accounting system is not perfect}

Good accounting work carrying out must have a sound system to support, but many SMEs accounting system at this stage is not perfect or missing. From the development and implementation of the basic system of inspection system for SMEs, quota management system, measurement and acceptance system, inventory system and other financial point of view, a lot of small and medium enterprises implement a large part of the water, some SMEs have never been performed, even these systems lack institutionalization, standardization and procedures management, which making the development of SMEs have no basis of accounting, the system can not find the appropriate safeguards.

\section{Unscientific management accounting work}

First, the accounting work institutions are not perfect. Most SMEs accounting agency has no complete independent system, and some do not even set up a special organization, they lack appropriate independent authority departments, making financial officers wear many hats, and later, accounting and internal structure is irrational, although fitted with appropriate position and despite the division of corporate financial officers, financial officers' business is not yet clear about orientation and work responsibilities, resulting in phase separation of power and 
responsibility. Second is centralized accounting management. Accounting works at the top of enterprise management, and has direct impact on the work carried out below. Leaders exist in centralization, family management of the phenomenon in many small and medium enterprises and in the organizational system use more vertical management model, they lack discussion of accounting theory, which leads to work independently in corporate finance management, financial operations and it is not fully in the core foundation of the role of business management. Furthermore, supervision and management is not clear.

\section{COMPLETE FINANCIAL ACCOUNTING MEASURES FOR SMES}

\section{A. Establish strict financial control system}

Accounting rules is the basic norms of work, the main system should be established in these areas: the separation of incompatible duties regime. SMEs are in accordance with the requirements of the principle of separation of incompatible duties, and there is a reasonable set of financial accounting and related jobs, a clear responsibility and authority, the formation mechanism of checks and balances. However, due to less business for SMEs, accounting only uses centralized accounting methods, designate a person to serve as treasurer, 2 to 3 people respectively are as a cashier accounting staff, general ledger, subsidiary ledgers, etc. establish clear responsibilities, mutual restraint on staffing; it is authorized to approve the control system.

\section{B. Change stereotypes, derivative of "people-oriented" management philosophy}

Who is the carrier of financial accounting, internal accounting work itself is human activity, and is carried out by people and the factors, and compared to other activities, the role of people is more obvious, and therefore changing the original appearance of SMEs to improve the level of financial control, we must enhance the quality of people, change the traditional concept of family constraints breakthrough, fully introducing all kinds of talent has become the top priority of the current task for SMEs. SMEs are also available through continuing education for accounting staff to improve their professional quality.

\section{To constantly improve them and expand financing channels}

Financing is the reliable guarantee of business strategy to improve long-term competitiveness, how SMEs effectively raise funds, in addition to policy support by the local government, it is mainly from improving their image and they should expand financing channels to consider, such as for corporate to improve the transparency of financial information, authenticity, to improve their level of interest, establish a good credit image, build their own unique set of internal credit rating system, based on good faith to provide relevant information to the corporate credit rating to the outside, and so many ways to improve their own image, to obtain the trust of social, financial sector, to obtain loans.

\section{Strengthen the internal audit; continue to strengthen internal supervision and restraint mechanisms}

On the one hand, SMEs should give full play to the role of internal audit. Internal audit is a special form of internal accounting controls, and essential work in accounting, internal audit is to ensure the premise of setting reasonable and independence and it should further intensify its efforts, by the internal audit department they are to complete evaluation of enterprise financial accounting work quality, which is consistent with the actual situation of SMEs, because: First, they have a separate internal audit organization; the second is the internal auditors are more familiar with the unit, to identify problems and to make recommendations in a timely manner, to take measures; Third, it could reduce the cost of management, and it is cost-effective. On the other hand, the government should play the role of audit and social audit, although mostly small and medium local businesses, local governments are also necessary for its oversight, but under market economy conditions, it should not interfere too much, but should policy give guidance, especially in the financial and accounting work by strengthening external oversight and restraint mechanisms fair assessment of SME financial accounting. By both supervising SMEs and implementation of financial accounting, financial accounting can change non-standard, arbitrary shortcomings in SMEs.

\section{E. Establish good communication system, implement a computerized financial control}

Good information and communication systems can be timely, comprehensive and correct information to provide business operations and communication between departments and staff. Currently, SMEs, although in the human, financial, material and other various conditions are difficult to meet the requirement, with the development of society and economy, competition in the market, it can implement a computerized financial control and establish good communication system, and it is imperative. Therefore SMEs in this respect should be strengthened investment. Establishing a good communication system can not only improve efficiency, but more importantly to improve the financial accounting standardization, quality of accounting information, and improve the level of the level of SME financial work. SME Financial Problems are more, but as long as there is careful analysis, thinking, we will always find a solution.

\section{SUGGESTIONS FOR FUTURE DEVELOPMENT OF SMES ACCOUNTING WORK}

\section{A. Intensify propaganda accounting law; strengthen the legal awareness of private entrepreneurs}

Accounting Law clearly stipulates that the responsible person must work for the unit of accounting, accounting information authenticity and legality is liable. Current 
accounting information distortion in a sense can be said the main reason is due to the responsible persons and legal consciousness. The relevant departments should step up publicity efforts method of accounting, and enhance awareness of the law of private property owners to abide by the national accounting laws and regulations, change perception of accounting work, emphasis on practical work, form knowing, and law-abiding, good atmosphere.

\section{B. Government intensifies supervision, construct and grasp Basic Accounting Standards}

Government taxation, auditing, business and other departments, should be irregularly inspect and supervise the accounting work of the private sector, increase the intensity, for the non-standard problems found in the inspection, they must be corrected promptly. Relevant departments should strengthen the guidance of private financial work, supervise the accounts of corporate law and accounting, and check whether the staff is working in the accounting qualification certificate holders and business development case, to accountants of no serious duties, we should cancel their qualifications, and they shall not engage in accounting work to promote standardization of accounting basis.

\section{Full play the role of the CPA, strengthen social audit}

CPA is a social intermediary organization with legal personality; their audit report is issued legally binding. We should give full play to their role, regularly register capital changes, and to other private financial revenue and expenditure audit of SMEs, we identify problems and propose solutions and timely advice, guide enterprises accounting work. Annual reports should be subject to private SMEs CPA audit industrial and commercial inspection can be carried out to ensure that the private sector accounting information is true, legitimate and effective.

\section{Strict establish accounts system, standard bookkeeping}

Implementing bookkeeping is an effective way to solve the current private SMEs accounting irregularities; especially the issue of individual businesses who does not prepare accounts in accordance with law. Through bookkeeping accounting services and agency providing high professional level, you can improve the quality of accounting work, standardized accounting. Standardize bookkeeping behavior, and guide private SMEs to have a reputable agency, hire a part-time social finance staff. For larger companies, they can use appointment System.

\section{E. Strengthen management and continue education for accounting personnel qualifications, strengthen ethical accounting staff}

Accounting method for accounting practitioners is to obtain qualifications to do a more clearly defined, we should increase assurance efforts. Strengthening the accounting staff continuing education and training, will be whether to participate in business accounting personnel training, which is as an important basis for the annual inspection passed. We can carry out short-term rotation classes, accounting knowledge contest and other activities, to constantly improve the professional quality of accountants, to take measures to put an end to nonqualification staff induction. Strengthen accounting staff dedication, honesty and law-abiding, objective and impartial, not cook the books, such as professional ethics, and constantly improve their ideological and theoretical level, creating a high-quality accounting team to better regulate accounting practices, improve the quality of accounting information for business management services.

\section{SUMMARY}

At this stage, there are insufficient accounting work in terms of SME financial management, institutional and personnel, to change the status quo there must be multipronged approach to enhance the quality of financial personnel, strengthen scientific management of financial operations, establish and improve mechanisms, incentives internal accounting development to all departments and positions to promote mutual cooperation and interaction between the development of SMEs accounting work, which provides good conditions for business management and contributes to obtain economic efficiency of enterprises.

\section{REFERENCES}

[1] Liu Zefu question of the existence of accounting work for SMEs [J] enterprise Herald, 2012,15: 149.

[2] Sun Xinzhang private SMEs accounting work problems and countermeasures [J] Jiangsu Provincial Institute of Socialism, 2003,03: 44-45.

[3] Zhu Yan small business accounting work on the problems and countermeasures [J] Enterprise Technology and Development, 2011,07: 56-58.

[4] Yang Yi Tang small and medium private enterprises Accounting Problems and countermeasures [J] career in accounting, 2008,02: 6769.

[5] Yu Changqun small and medium private enterprises Accounting Problems and countermeasures [J] Hubei Radio \& TV University, 2007,12: 100-101.

[6] Zhang Cong small business accounting work of the existing problems and countermeasures [J] modern economic information, 2015,01: 217.

[7] Zhang Yan private enterprise accounting work problems and countermeasures [J] Chinese foreign investment, 2013,11: $154+156$. 